NASA Technical Memorandum 100927

AIAA-88-3288

\title{
Development of a Liquid-Fed Water Resistojet
}

W. Earl Morren and James R. Stone

Lewis Research Center

Cleveland, Ohio

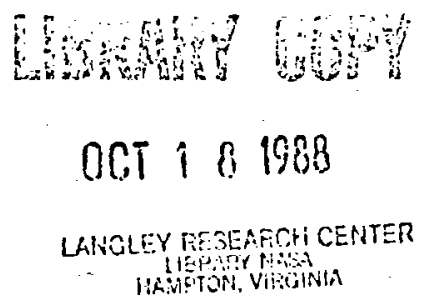

Prepared for the

24th Joint Propulsion Conference

cosponsored by the AIAA, ASME, SAE, and ASEE

Boston, Massachusetts, July 11-13, 1988

\section{N/SN}




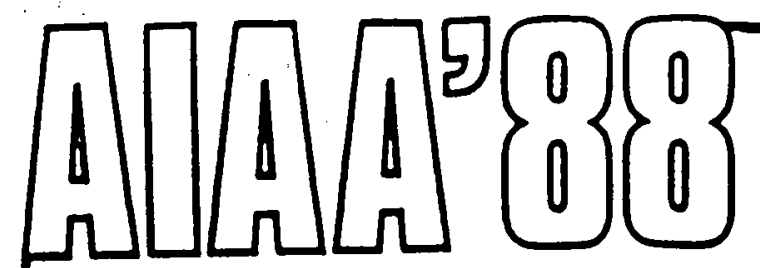

AIAA-88-3288

Development of a Liquid-Fed Water

Resistojet

W. Earl Morren and James R. Stone, NASA Lewis Research Center, Cleveland, $\mathrm{OH}$

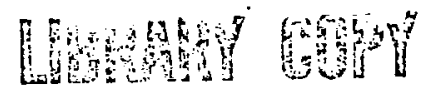 \\ OCT 181988 \\ LANGLY RESEAPCH CENTER \\ HAMPOAN, vikGitha \\ AIAA/ASME/SAE/ASEE 24th JOINT PROPULSION CONFERENCE JULY 11-13, 1988/Boston, Massachusetts}

For permission to copy or republish, contact the American Institute of Aeronautics and Astronautics 370 L'Enfant Promenade, S.W., Washington, O.C. 20024 


\section{DEVELOPMENT OF A LIQUID-FED WATER RESISTOJET}

W. Earl Morren and James R. Stone

National Aeronautics and Space Administration

Lewis Research Center

Cleveland, Ohio 44135

\section{Abstract}

A concept for a forced-flow once-through water vaporizer for application to resistojet thrusters was evaluated as an element of a laboratory model thruster and tested to investigate its operating characteristics. The vaporizer design concept employs flow swirling to attach the liquid flow to of the boller chamber wall, providing for separation of the two fluid phases. This vaporizer was modifled with a nozzle and a centrally-located heater to faclilitate vaporization, superheating, and expansion of the propellant, allowing it to function as a resistojet. Performance was measured at thrust levels ranging from 170 to $360 \mathrm{mN}$ and at power levels ranging from $443 \mathrm{~W}$ to $904 \mathrm{~W}$. Maximum measured specific impulse was $192 \mathrm{sec}$.

\section{Introduction}

This paper describes the progress of a program to develop a resistojet system capable of operation on water propellant. Multipropellant resistojets, for which water is a candidate propellant, have been baselined as the low-thrust propulsion system option for the Space Station.1 Water resistojets have also been baselined for orbit maintenance duty on the man-tended Industrial Space Facllity scheduled for launch in the early 1990's. 2

The use of water as a resistojet propellant for manned or man-tended platforms has a number of attractive features. Scavenged waste water which might otherwise have to be returned to Earth could be used to provide impulse for drag make-up or orbit control. Space systems which operate on water economies could store liquid water easily in small, low-pressure tanks, electrolyze this water for use in hydrogen/oxygen rockets to perform high-thrust propulsion tasks, and use water from the same storage tanks to feed water resistojets for low-thrust propulsion. Furthermore, the benign chemistry of water and steam makes it wellsuited to manned systems, where toxicity and contamination are of great importance.

Water was one of the candidate propellants for a blowaste resistojet system investigated as part of the Manned Orbital Research Laboratory (MORL) program conducted during the early 1970's. Preliminary evaluation of basic components including thrusters, steam generator, compressors, and pumps was undertaken. 3,4 The MORL program and the associated biowaste resistojet technology work was terminated in the early 1970's.

Recentiy, a program was initlated to develop technology for a water vaporizer capable of providing steam to the multipropellant resistojet currentiy baselined in the Space Station propulsion system. The water vaporizer designed under the MORL program was investigated, but refected in favor of a new design which is discussed in this paper. During this technology program, it was determined that a simple, integrated vaporizer/ superheater could be bulit that would serve as a one-plece thruster. Laboratory model versions of this thruster were designed, constructed, and tested to verify the design concept and investigate its operational characteristics. For application to Space Station, where both gaseous and liquid propellants might be used, a separate vaporizer based on this technology might be of interest. This paper will discuss the basic bolling theory used to arrive at this design, present a detailed description of the design, present the results of performance mapping, and discuss the characteristics of a liquid-fed water resistojet propulsion system.

\section{Theory}

The boller required for application to water resistojets is the forced-flow, once-through type, in contrast to the simpler and more common pottype boilers. To integrate with a continuous-flow propulsion system, the subcooled liquid is converted into superheated vapor in a single pass through the boller. Extensive liquid bolling research was conducted in the 1960's and early 1970 's as summarized by Stone, et al.5 For the reader's convenience, some basic considerations important to the design of forced-flow oncethrough bollers are repeated in this section as presented in Ref. 5. However, this information has been condensed significantly to include only that which is germane to water resistojet design.

\section{Background}

During the bolling of a liquid flowing through a channel, several heat transfer regimes are encountered. A typical case is fllustrated in Fig. 1. The liquid to be vaporized enters the channel and is heated in the liquid phase to the point where bubble nucleation first occurs. Nucleate bolling continues until enough vapor is generated that the resulting increase in velocity is sufficient to suppress nucleation. Beyond this point, heat is added to a thin liquid film and vaporization occurs at the liquid-vapor interface. Throughout these bolling regimes, liquid is being entrained in the vapor core. Despite any redeposition of liquid from the core to the film, at some point there is no longer sufficlent liquid to wet the wall. The liquid film breaks down with a large reduction in heat transfer coefficlent, often more than an order of magnitude. This transition has variously been termed "bolling crisis," "departure from nucleate bolling," and "burnout," as well as other names. This film breakdown is generally followed by a transitional regime wherein a considerable amount of liquid remains on the wall. Eventually, only a few liquid droplets remain on the wall, and most of the heat added through the wall goes into heating the vapor. It then becomes difficuit to vaporize the remaining droplets. 
To design a forced-flow boller, it is necessary to predict the heat transfer and pressure drop characteristics of each of these regimes. This problem is complicated by the wide varlety of possible two-phase flow regimes and by vartous thermodynamic nonequilibria, such as subcooled bolling and liquid droplets in superheated vapor. It is also very important that the boiler not interact with other components of the flow system to produce instablilities. The following sections describe these problem areas in more detail.

\section{Stability}

The problem of boller instability is quite serlous in systems using forced-flow once-through bollers. Such instabllity leads to poor performance of the system and can even lead to fallure. Lowdermilk, et al, 6 found that flow oscillations could cause a large decrease in heat flux at the bolling crisis. The instability could be prevented by restricting the flow upstream of the boller section, thereby decoupling or isolating the boller from the upstream liquid leg, which can also contain vapor or gas volds. In this regard, they found that a compressible volume upstream of the boiling section had a destabilizing effect. Similar results were reported by Aladyev, et al. 7 Jeglic ${ }^{8}$ noted three types of instablitity that may occur in two-phase flow: interfacial, flow excursion, and oscillation. One important class of osciliation instability is that due to dynamic coupling of the boller feed system and the subcooled bolling region. Jeglic and Grace ${ }^{9}$ observed flow oscillations in subcooled bolling. These oscillations were strongly dependent on the thermodynamic conditions existing in the boller.

\section{Flow Patterns}

A multitude of flow patterns is possible for two phases flowing concurrently, as is the case in a boller. This makes it difficult to develop reliable correlations of two-phase pressure drop. heat transfer coefficient, and bolling crisis. Some of the flow patterns typically encountered are shown in Fig. 2. These are only a few; others are plug, wave, dispersed, fog, spray-annular, froth, and rivulet. Most flow pattern studies have been with adlabatic, two-component systems, 10-16 although some data exists for diabatic conditions. 17-24 These results are generally presented in terms of flow pattern maps similar to that of Baker. 10

\section{Heat Transfer}

Although there have been numerous studies of bolling heat transfer, there is still no generally applicable means of prediction avallable, especlally for high-density-ratio fluids such as. low pressure water. This is especlally true of the subcooled bolling regime, where nonequilibrium effects are important, although the subcooled boiling heat transfer correlations $25-28$ give reasonable design approximations in many cases.i Some correlations have been proposed for net-quality (1.e., the steam.quality obtained from an overall fluid heat balance assuming thermodynamic equilibrium) bolling heat transfer. 24,29-36

Typical variations of the bolling heat transfer coefficient and quality with axial distance through a boller are shown in Fig. 3. The heat transfer coefficient is normalized to the allliquld value. Bolling heat transfer coefficients are much higher than the liquid values prior to the bolling crisis and then decrease rapidly with distance, eventually reaching a value on the order of a gas heat transfer coefficient. Three heat transfer regimes are defined in Flg. 3: the subcooled regime, from the inception of boiling to zero heat-balance quality; net-quality bolling prior to the crisis; and the post-crisis regime.

\section{Boliling Crisis: Liquid Film Breakdown}

When there is no longer sufficient liquid on the heated wall to maintain a continuous liquid film, the liquid film breaks down and a drastic reduction in heat transfer coefficient occurs. This transition will be referred to as "bolling crisis" in this paper. Although the bolling crisis has been the subject of numerous experiments, analyses, and correlations, there remains much. uncertainty in predicting the bolling crisis for any particular system. Much of this uncertainty can be attributed to filow system characteristics and instablities.

The importance of postponing boiling crisis poses special problems for operation in low-gravity environments, since insuring liquid-solid adhesion requires some local application of an attractive force (1.e., acceleration or ilquid surface tension). The need to maintain proper solid-liquid. contact can be avoided, however, if the liquid is heated radiatively. As an example of the potential for radiative heating of 1 iquid water, Fig. 4 shows an infrared absorption spectrum for a $0.1 \mathrm{~mm}$ thick liquid water film as well as Planck's spectral distribution of emissive power for a black source at a temperature of $1000 \mathrm{~K}$. From this plot, it is clear that nearly all of the incident radiation not reflected at the liquid-vapor interface wlll be absorbed by a thin film of liquid for source temperatures on the order of $1000 \mathrm{~K}$.

\section{Drying of Vapor}

In conventional stationary power plants, generally no attempt is made to vaporize all the incoming liquid. Instead, the vapor and liquid are separated, and the remaining liquid is recirculated. However, compact systems, such as those for space use, are usually designed to vaporize all the incoming liquid. This is the "oncethrough boller" concept. In order to dry the vapor, the two-phase mixture is often swirled within the boller, thus centrifuging the liquid to the heated wall, where it can be vaporized.

This swirl has generally been obtained by means of inserts; by colling a tube, or by a combination of inserts and tube colling. These approaches have resulted in varying degrees of Improvement, as in the mercury boller. development programs. 37-40. These swirl techniques improve overall performance, but they increase pressure drop and tend to promote rivulet flow with its assoclated problems, such: as. vapor superheat with liquid still present.37-41 Part of the problem may be due to the shear of high-velocity vapor on the liquid, causing the liquid film to be torn apart. Another method of drying is the crossflow heat exchanger, wherein the two-phase flow passes through a bank of heated tubes on which the liquld impinges and is vaporized. 42 
A more novel approach to producing dry vapor is to rotate the boiler, as shown schematically in Fig. 5. A rotating boller has many. obvious advantages. 43-44 It is insensitive to gravity field and orientation. The liquid-vapor interface is rather sharp and stable, yielding a steady flow of both vapor and liquid. Because of the centrifugal action in the vapor space, the exit vapor should have low moisture content (high quality). Heat fluxes considerably higher than for pool boiling in the presence of standard gravitational acceleration should be attainable. The use of a rotating boller, however, requires moving parts and rotating seals. The cyclone boller concept (Fig. 6) represents an attempt to exploit the benefits of the rotating boller without the need for moving parts. The liquid or two-phase feed mixture flows into the boller chamber tangentially in such a manner that a vortex flow pattern is established, and vaporizes due to the pressure drop across the inlet as well as heat applied through the chamber wall. The liquid is centrifuged to the wall, and is then driven toward the apex of the cone by secondary flow effects 45 augmented by surface tension and, for some cases, gravity, while the vapor exits from the top.

\section{Apparatus and Procedure}

\section{Vaporizer/Thruster Design}

The design concept for a liquid-fed water resistojet evolved from an initial goal of providing a water vaporizer to supply steam to a separate resistojet. The first concept pursued was based on the cyclone vaporizer discussed previously (Fig. 6) and is shown in Fig. 7. Liquid was injected tangentially into a boller chamber through a $0.023 \mathrm{~cm}$ diameter hole. The boller chamber consisted of a $2.3 \mathrm{~cm}$ diameter by $8.4 \mathrm{~cm}$ long cylinder terminated at the liquid inlet end by a flat cap, and at the opposite end by a cone of $30^{\circ}$ included angle. Heat was added to the 11 quid through the boiler chamber wall to effect vaporization. This device proved to be troublesome to operate because the 11 quid film would not adhere to the wall, and wall temperatures tended to rise several hundred degrees above saturation level. This caused significant reductions in heat transfer efficiency. Even when stable operation was achieved in the presence of reasonable wall temperatures, the exhaust products were never of $100 \%$ quality (i.e., some liquid droplets remained entrained in the flow stream). This was probably due to Inadequate flow swirling in the boller chamber.

The experiences with the first water vaporizer design prompted the installation of a colled wire along the inside of the boller chamber wall to direct the incoming liquid along a spiralled path. This change insured that the radial accelerations induced by the curved flow path could be maintained along the length of the boller chamber wall. Concurrently, it was decided that higherquality steam could be obtained if the heater were relocated to the center of the boller chamber. There, it could operate at temperatures well in excess of saturation, levels, radiate the heat required for vaporization to the liquid on the boller wall, and superheat the vapor as it escaped the boller chamber. The colled heater was wound around the superheater tube. The superheater tube contained an insert which increased the Reynolds number of the flow over that of a simple hollow tube. A flow-spiralling wire within the flow passage of the superheater served to throw any stray liquid droplets entering the superheater toward the outer side of the annulus (nearest the heater) to aid in completing vaporization. This device produced superheated vapor with boller chamber wall temperatures near the saturation level. The unique features of this design concept were that it employed radiative coupling between the heater and liquid for vaporization and convective coupling between the heater and vapor for superheating, all using a single heater. The radiative coupling was made possibie by the fact that liquid water films as thin as $0.1 \mathrm{~mm}$ absorb over 90 percent of the incident radiation not reflected at the liquid surface for source temperatures of about $1000 \mathrm{~K}$.

Since vaporization and superheating were shown to be feasible with a single unit, it was decided to attach a nozzle to the outlet of the superheater so that the exhaust products could be expanded to produce thrust. At this point, the water vaporizer became a water resistojet. A further refinement included the addition of six thermocouples embedded in the wall of the superheater to serve as diagnostic tools as well as inputs to a power controller. Figure 8 shows a sectional drawing of the water resistojet.

The laboratory model water resistojet components, including boller chamber, superheater, end cap, and nozzle, were fabricated from stainless steel. The heater cabie consisted of a nichrome center conductor wire, a layer of magnesium insulation, and an Inconel sheath which was swaged to compact the magnesia insulation around the heater wire. The heater operated at temperatures of $\sim 1000 \mathrm{~K}$.

The laboratory model version of this design concept employed some features intended to ease changes in the liquid injector channel, heater size or configuration, and other internal details. The boller chamber was formed from two pleces: the chamber wall and end cap. The liquld injector channel was located in the end face of the chamber wall, which was clamped to the Inner face of the end cap by means of two large flanges. The end cap served as a mounting stage for the solenold valve/flow restrictor assembly and the heaterl superheater/nozzle assembly. Figures $g(a)$ and (b) show photographs of the water resistojet fully assembled and disassembled, respectively.

\section{Feed System}

The water feed system used to supply the water resistojet is shown schematically in Fig. 10. The basic components are the stainless steel propellant reservoir, a regulated supply of nitrogen pressurant, a graduated sight glass for mass flow measurement, and a shut-off valve between the reservoir and the sight glass. This system allowed the water resistojet to be supplied with liquid at a relatively constant inlet pressure. The mass flow rate through the system was controlled by the pressure difference across the flow restrictor at the inlet to the water resistojet. The chamber pressure within the resistojet varied significantly under transient conditions, either as a result of a deliberate change in operating conditions, unintended flow or power 
perturbations, or instabilities caused by an improper matching of input power and mass flow rate. Initially, this caused the mass flow rate into the water resistojet to vary sufficiently to send the thruster into an unstable operating regime if the input power and feed pressure were held constant. This problem was eliminated by adding a commercially-available flow restrictor to the inlet of the later resistojet. This flow restrictor was capable of producing highly localized pressure drops of up to $1.6 \mathrm{MPa}$ at fiow a rate of $0.2 \mathrm{~g} / \mathrm{sec}$. This flow rate correspond to a boller chamber pressure of $\sim 0.5 \mathrm{MPa}$ in the laboratory model water resistojet. Thus even a 10 percent change in boller chamber pressure would result in an inlet pressure drop change of only 3 percent, with a corresponding mass flow rate change of about 1.5 percent. A solenold valve located directly upstream of the flow restrictor provided for propellant shut-off. The proximity of the solenold valve and flow restrictor to the injector channel minimized the liquid volume downstream of the valve. It was necessary to evacuate this volume each time the thruster was shut down before the thrust level dropped to zero.

The water used for all tests was distilled to remove impurities that might be deposited on thruster or feed system surfaces. Mass flow rate measurements were obtained using of a graduated sight glass. This method falled to expose fluctuations in flow rate which occurred over relatively short periods $(<1 \mathrm{~min})$ due to the batch-process nature of the measurement. However, callibrations proved the accuracy and precision to be better than 1 percent for constant-flow conditions.

\section{Thruster Characterization}

The ability to throttle the water resistofet was a primary design goal of this program. Therefore, it was necessary to demonstrate the operating capabilities of this design over as wide a range of thrust levels and power levels as possible. Data were obtained for thrust, mass flow rate, heater voltage and current, feed pressure, and three heater temperatures for a variety of operating conditions. Feed pressure was measured just upstream of the solenoid valve located at the thruster inlet (Fig. 8). Three heater temperatures were monitored during performance characterization: the first was approximately $0.64 \mathrm{~cm}$ from the inlet end of the superheater, and the remaining two were located $\sim 2.5$ and $5.1 \mathrm{~cm}$ downstream of the first ( $F \mid g .8$ ). These temperature measurements were used to diagnose causes of instablility and as inputs to a pulsed dc power controller. Additional thermocouples were installed on the cylindrical section of the boller chamber wall. but could not be monitored during thrust measurements due to limitations on telemetry imposed by the thrust stand.

A typical operating session began with a brlef ( $<1 \mathrm{~min}$ ) preheat of the heater to a temperature of $\sim 800 \mathrm{~K}$. The power level at whlch this preheat occurred was higher than the anticlpated equllibrium value due to pecullarities in the translent characterlstics of the water resistojet. These characterlstics will be discussed in detall later in this paper.' With the heater preheated, the solenoid valve was opened to initiate flow. After the thrust level had stablilized, the power level was reduced to a value which ylelded steady operation and minimized heater temperatures. Mass flow rate, thrust, and heater temperature data were recorded only after all monitored parameters had stabilized.

Test $\mathrm{Cell}$

Thruster characterization tests were conducted in a vacuum facility measuring $1.1 \mathrm{~m}$ in diameter by $4.6 \mathrm{~m}$ long, and equipped with a mechanical blower backed by a rotary piston vacuum pump. This facility was capable of maintaining tank pressures below $27 \mathrm{~Pa}(0.2$ torr) during operation of the water resistojet at maximum thrust levels. The minimum achievabie tank pressure was about $1 \mathrm{~Pa}$ ( 0.01 torr).

Thrust was measured using a calibrated displacement type thrust stand. The estimated uncertainty of the measured thrust values was $<1$ percent. This thrust stand has been described in detall in Ref. 46.

Power was supplled to the water resistojet heater by a dc power supply capable of delivering up to $100 \mathrm{~V}$ and $100 \mathrm{~A}$. This power supply was operated in a voltage-limited mode curing all tests. A pulsed dc power controller employing a heater temperature feedback loop was designed, constructed, and integrated with the water resistojet, although time constraints did not permit a thorough characterization of this system.

\section{Results and Discussion}

\section{Water Resistojet Performance}

The use of water as a resistojet propellant differs significantly from gas, primarily due to the requirement that the fluid undergo a phase change before useful thrust can be obtained. Steam table data 47 show that $\sim 0.52 \mathrm{MJ} / \mathrm{kg}$ are required to bring the liquid from a storage temperature of $290 \mathrm{~K}$ to saturation temperature at a boller chamber pressure of $0.4 \mathrm{MPa}$. Vaporization of liquid water at that pressure requires an dditional $2.13 \mathrm{MJ} / \mathrm{kg}$. Although the energy requirements for preheating and vaporization are individualiy sensitive to ambient pressure, their sum is highly insensitive to pressure. Figure 11 shows that for the ratio of electric power to mass flow rate ranging from 3.5 to $5.0 \mathrm{MJ} / \mathrm{kg}$, the fraction of input electric power required to preheat and vaporize the propellant (the shaded region) varles from 76 to 53 percent. From this, it is clear that the water resistojet must expend a large quantity of power for preconditioning of the propellant over its entire operating range. still more power must be expended to superheat the vapor, since expansion of saturated vapor to a hard vacuum would likely result in condensation in the nozzle. The sum of the fractions of input electric power dissipated by superheating of the propellant and thermal losses is shown by the unshaded regton in Fig. 11 .

Figure 12 shows the distribution of Input electric power utilization within the water resistojet for an operating point in the middle of the demonstrated range of the test thruster. The requirements for preheating and vaporizing of the propellant represent nearly 60 percent of the total power consumed, while superheating of the 
steam accounted for only about 20 percent.. The remaining input power was dissipated in thermal losses, both radiative and conductive. The distribution of power shown in Fig. 12 was obtained by choosing an average set of operating conditions: $270 \mathrm{mN}$ thrust, $180 \mathrm{sec}$ specific impulse, a mass flow rate of $150 \mathrm{mg} / \mathrm{sec}$, and a power level of $680 \mathrm{~W}$. The incoming liquid was at $290 \mathrm{~K}$. The input powers requlred for preheating and vaporizing are readily calculated using steam table data, given the mass flow rate. Calculation of the input electric power expended in superheating the water vapor involves estimating the difference between the stagnation enthalpy of the propellant (immediately upstream of the nozzle) and the enthalpy of the saturated vapor, then multiplying by the mass flow rate. The stagnation enthalpy. can be estimated by:

$$
h_{0}=\frac{\tau I s p g_{e}}{2 \dot{m} n_{n o z}^{2}}
$$

Where $\tau$ is thrust. Isp is specific impulse, $\dot{m}$ is mass flow rate, ge is standard gravitational acceleration, and $n_{n o z}$ is the nozzle specific impulse efficlency (defined as the ratio of the actual specific impulse to that obtainable from an ideal nozzle with identical stagnation conditions). The quantity given by Eq. (1) is also the integral of the constantpressure specific heat, $C_{p}$, over the temperature range from $0 \mathrm{~K}$ to the stagnation temperature, $T_{0}$ :

$$
h_{0}=\int_{0}^{T_{0}} C_{p}(T) d T
$$

The enthaipy given by Eq. (2) is tabulated as a function of temperature in standard tables of thermodynamic properties, 48 so the fluid stagnation temperature may be obtained readily. Determination of saturation conditions can be made by direct measurement of either boller chamber pressure or the temperature of the liquid in the boller chamber. Having established the saturation and stagnation temperatures, the enthalpy rise from saturation level to stagnation temperature can be obtained from standard steam tables. The power required for superheat is then:

$$
\left.\operatorname{Pe}\right|_{\substack{\text { huper- } \\ \text { heat }}}=\dot{m}\left[h\left(T_{0}\right)-h_{g}\left(T_{\text {sat }}\right)\right]
$$

The nozzle specific impulse efficlency used in Eq. (1) must be assumed. The minimum value for the water resistojet was probably 0.92 , since a value lower than that would have driven the estimated propellant stagnation temperature to a level inconsistent with heater temperatures measured near the exit of the superheater. Increasing the assumed nozzle efficiency reduces the estimated stagnation temperature of the steam and thus the estimated superheat power. This increases the estimate of thermal losses, which are obtained by subtracting the sum of preheat, vaporizing, and superheat powers from the total power input. The uncertainty in the estimate of the superheat power fraction, and, therefore, the thermal loss fraction, is \pm 3 percent. This uncertainty is represented by the cross-hatched region separating the super- heat and thermal loss slices in Fig. 12. It should be noted that a nozzle efficlency of 0.92 is higher than publi shed data for resistojet thruster nozzles, 49,50 so the actual losses for the operating point represented by Fig. 12 are probably closer to the lower end of the range shown. The relationship between the fractions of input power expended in superheating and losses effects the specific impulse. Higher specific impulse requires higher stagnation temperature, which in turn requires a greater amount of superheat. This assumes no significant change in nozzle efficiency occurs over the operating range. This assumption appears reasonable since the throat Reynolds numbers for the water resistojet ranged from 5200 to 11000 and Refs. 49 and 50 indicate that nozzle efficiencies remain relatively constant over that range of Reynolds numbers.

Thermai losses due to radiation proved difficult to quantify due to limitations in the temperature measurement telemetry on the thrust stand. However, temperature surveys conducted in the absence of thrust measurements indicated that the outer surface of the boller chamber typically operated in the range of $30 \mathrm{~K}$ below or above the saturation temperature for the boller chamber pressure (Fig. 8 for locations of external thermocouples). The observed temperatures were generally lower near the liquid inlet. increasing toward the polnt where the cylindrical and cone sections of the chamber were jolned. No temperature measurements were made on the flanges, end cap, or mounting bracket. An estimate of the radiative losses was made by assuming the entire boller chamber wall and both flanges were operating at saturation temperature (about $420 \mathrm{~K}$ ), the temperature of the nozzle region was $900 \mathrm{~K}$, and the end cap temperature was midway between these two values. It was further assumed that the portion of the heater cable located outside the boller chamber operated at $1000 \mathrm{~K}$. Emittance values for the slightly oxidized boller chamber wall and flanges were taken at 0.4 , while the more heavily oxidized end cap and nozzle regions were taken to be black. Conductive losses were estimated by assuming the mounting bracket temperature fell from saturation value to room temperature over its $2.5 \mathrm{~cm}$ length. Losses through the propellant feed tube were neglected due to the large thermal capacity of the Incoming liquid acting as a coolant. Application of these assumptions resulted in estimates of 1 and 10 percent of the total input electric power for the conductive and radiative losses, respectively. Still, the sum of these values is well below those shown in Fig. 12, suggesting that nozzle efficiencles used in that figure were too high and/or the assumed outer surface temperatures and emittances were higher than estimated. Outer surface temperatures could have been higher than estimated if the walls of the boller chamber were not completely coated with liquid on their inner surface. This would increase the radiative gain of that surface, increasing radiation losses. Further measurements of external temperatures and emittances are required to reduce the uncertainty.

Figure 13 illustrates the relation between measured specific impulse and the ratio of input electric power to mass flow rate for the water resistojet. Also shown are isograms for the overall efficiency of the water resistojet. This efficlency was obtained by dividing the measured thrust power by the input electric power. The 
sensible energy of the incoming liquid was neglected in this calculation since no useful thrust could be obtained from the propellant in its standard state. The overall efficlency of the: water resistojet ranged from 31 to 38 percent, and tended to increase with the ratio of input power to mass flow. This trend makes sense because about 50 to 75 percent of the power expended at a given flow rate goes to preheating and vaporizing the liquid. Thus any marginal increase in power at that mass flow rate would go toward increased superheating, which would lead to higher specific impulse. The overall efficlency should increase under such conditions because efficiency varies with the square of specific impulse and inversely with input electric power. This assumes that increases in thermal losses are negligible, and that nozzle losses remain relatively constant (using the same argument given above regarding nozzie efficiency). In order for thermal losses to remain constant, the fraction of the boller chamber wall wetted by liquid should not change with the ratio of power to mass flow rate.

Two of the points shown in Fig. 13 appear to fall out of the relatively tight grouping of the remaining nine points. The reasons for these discrepancies are not clear from the avallable data. More thorough thermal mapping will be required to identify the causes. Another characteristic which merits further investigation is the presence of hysteresis in thruster performance. The equilibrium heater temperatures observed when approaching an operating point from a higher temperature were often as much as 100 to $200 \mathrm{~K}$ higher than if the thruster were brought to equilibrium from a cold start or lower-temperature operating point.

Figure 14 shows that the ratio of input electric power to thrust remained very nearly constant over the entire operating range at a value of $\sim 2.5 \mathrm{~W} / \mathrm{mN}$. The line shown in this figure does not represent constant mass flow rate or specific impulse. These parameters increased by 89 and 17 percent, respectively, over the operating range. Rather, it is simply the locus of observed thrust and power combinations over the entire operating range.

For a given thrust level, operation at input power levels significantly below the line in Fig. 14 result in a condition of unstable thrust and mass flow rate. The extent to which the water resistojet could be run stably below the line cannot be quantified with the avallable data. The most likely cause of instability at low power levels is thought to be incomplete vaporization of the liquid within the boller chamber. leading to migration of liquid droplets into the superheater. This would cause the superheater temperature to fall, further reducing the radiative heat transfer to the liquid on the boiler chamber. wall as well as the quality of the steam entering the superheater. Since the superheater operates at temperatures much higher than saturation values; it cannot act as an efficient boiler. Liquid droplets which enter the superheater can, therefore, migrate to the nozzle and cause sporadic thrust output or nozzle clogging.

For a given thrust level, increasing the input power above the 1 ine in Fig. 14 increases the heater temperature. A desirable heater temperature limit for long life, based on the heater manufacturer's recommendation, would be $1000 \mathrm{~K}$. Heater temperatures above $1000 \mathrm{~K}$ could be tolerated if the heater materials were changed to platinum or some very high-temperature nickel alloy. Little effort was made to operate the thruster at power levels greater than those required for stability, since the minimum heater temperatures required for stability were often equal to or greater than the target of $1000 \mathrm{~K}$. Heater temperatures tended to be higher than desired because the heater was constrained to fit inside an existing boller chamber, and the surface area could not be chosen to radlate the necessary power levels at lower temperatures. This problem has been addressed in the design of a new laboratory model water resistojet which includes a three-fold increase in heater surface area over the existing thruster.

Increasing input power above that shown in Fig. 14 can also lead to excessive wall temperatures. Such a condition is undesirable more from a thermal loss standpoint than from any material property 1 imitations or stablilty considerations. Operating conditions where large fractions of the boiler chamber wall are dry lead to radiation transfer from the heater to the wall, causing high wall temperatures and increased radiative losses from the thruster. A vaporizer concept which relies on conduction from the heat source surface to the liquid would be sensitive to high surface temperatures. However, bolling heat transfer in a radiatvely-coupled vaporizer does not require intimate contact between the liquid and wall.: The radiatively-coupled swirled-flow water resistojet proved highly tolerant of excessive wall temperatures. For example, a situation was observed during one operating session when stable operation was achieved at very low thrust levels (about $90 \mathrm{mN}$ ) with portions of the boller wall at temperatures in excess of $900 \mathrm{~K}$. Recovery from this condition was a simple matter of increasing the flow rate while holding input power constant. One possibility for maintaining a low boller chamber wall temperature is to utliize the liquid feed line as a heat.sink by colling it around the outside of the boller chamber. In this manner, waste heat could be used to perform some of the preheating of the propellant before it enters the boller chamber. Care must be taken, however, to avoid localized overheating, which could cause boiling in the feed line and induce flow instabilities for the entire system.

\section{Water Resistojet Transient Characteristics}

A system intended for intermittent operation over a range of conditions must have predictable startup, shutdown, and quasi-steady state transient characteristics. The tests of the water resistojet discussed in this paper were conducted without the benefit of any automated power control. Thus power levels were varled manually by changing the heater voltage in response to readings from a series of thermocouples located on the heater. This presented particular problems upon startup. The mass flow rate immediately after opening of the solenold valve was that corresponding to a pressure drop across the inlet flow restrictor equal to the absolute feed pressure. As the incoming fluid vaporized the boller chamber pressure increased, causing the mass flow rate to drop until it stabllized when the boiler chamber pressure stablilized. The fact that large variations in mass flow rate were experienced during startup indicates the need for careful power 
modulation. This was difficult to perform manually, since it required the operator to estimate the initial power requirement as well as the rate at which the power level needed to be reduced to avold excessive thruster temperatures. Consequently, completely smooth: startups using manual power control were a rare occurrence. The solution to this startup problem was to use an automated power controller capable of maintaining a proper balance between power and mass flow rate. A device was designed that serses the heater temperature and adjusts the duty cycle of a pulsed dc output signal to maintain that temperature at or near some preset reference value. 51 Heater temperature was chosen as the control parameter because it was relatively easy to measure and because it provides an indication of the minimum power level required to sustain operation at given mass flow rate. An insufficient power level will result in a sharp drop in heater temperature; first near the inlet to the superheater tube, then over the entire heater length. One drawback to this method of control is that is that no indication is given of the integrity of the liquid film on the boller chamber wall. That is, the power with which the heater temperature controller drives the heater may be sufficient to cause dry spots to develop on the chamber wall, causing higher radiative losses than are desirable. This problem could be overcome, however, by programming the reference temperature in the power controller to vary according to the propellant feed pressure, providing lower heater temperatures at lower feed pressure (and mass flow rate) levels. A laboratory model version of such a power controller was constructed and integrated with the water resistojet. While sufficient time was not avallable to perform a thorough mapping, a brief checkout of this system proved it capable of providing smooth startup transients.

Changes in thrust level (quasi-steady state) were significantly smoother and more predictable than the initial startup, even without the benefit of automatic power control. Reductions in thrust level were accomplished by simultaneous reductions in propellant feed pressure and heater power in proportions which would maintain the ratio of power and thrust given by Fig. 14. A step reduction in feed pressure resulted in a step reduction in mass flow rate, but thrust lagged by several seconds due to the volume of liquid present in the boiler chamber. As this liquid volume was reduced due to the lower mass flow rate, thrust began to decrease gradually. This caused the pressure drop across the inlet, as well as the mass flow rate, to increase. This situation tended to stabilize in 1 to $2 \mathrm{~min}$. Higher thrust levels were achleved by proportional increases in power and feed pressure. The step increase in feed pressure produced a gradual increase in thrust level, which lagged the immediate response of the mass flow rate. As thrust level increased, so did the boller chamber pressure. This caused the mass flow rate to decrease, which reduced the power requirement to maintain stable operation. Thus, an increase in thrust level was analogous to the startup transients discussed earlier.

\section{CONCLUSIONS}

A resistojet capable of operation on water propellant was designed and constructed in the form of a laboratory model, and tested to investigate its operational characteristics. The propeliant input is liquid water at room temperature. Tangential injection of the llquid water into the boller chamber, as well as the use of a flowspiralling wire along the length of the boller chamber wall induce radial accelerations which facilitate separation of the two fluid phases. A single sheathed cable heater located centrally in the boller chamber provides the power required to preheat, vaporize, and superheat the propellant before it is expelled through the nozzle. The heater typically operates at temperatures of $1000 \mathrm{~K}$, and transfers heat to the liquid radiatively. The formation of a llquid film on the boiler chamber wall allows it to operate at saturation-level temperatures, while the internally-located superheater produces high-temperature effluent.

The phenomena governing the operation of resistojets using water propellant differ in several signiflcant ways from those of gas- or 11quid hydrazine-fed resistojets. Foremost among these is the fact that water requires coplous amounts of energy to preheat to saturation temperature and vaporize. This is the primary reason for the low measured values of thrust power efficlency relative to resistojets operating on other propellants. Thus, it is clear that water is a poor choice of propellant, unless other system considerations override. Such considerations would include synergism with other components of a space system operating on a water economy, ease of storage of the propellant, and ease of handling and refueling in a manned system.

Typical gas-fed resistojets can operate with no power input at all, while water resistojets require at least enough to vaporize and slightly superheat the propellant to prevent nozzle clogging due to condensation. The ratio of electric power to mass flow rate is bounded at the upper limit by materials capabilities within the thruster, regardless of what propellant is used. However, the water resistojet described in this paper must operate at combinations of power and mass flow rate that insure maximum wetting of the boller chamber walls in order to minimize thermal losses.

Start-up transients differ from those of gasfed thrusters as well. Gas-fed thrusters are capable of producing thrust immediately upon initiation of mass flow, and the relationship between mass flow rate and input power has no effect on the stablilty of the startup. Water resistojets require preheat time before initiation of mass flow. Then an initial surge of power greater than the desired equilibrium value is required to deal with an inrush of liquid brought on by a relatively large pressure drop across the inlet when the propellant shut-off valve is first opened.

The water resistojet described herein has been demonstrated to be operable over a range of thrust levels from 170 to $360 \mathrm{mN}$ and at input electric power levels from 443 to $904 \mathrm{~W}$. Specific impulse ranged from 164 to $192 \mathrm{sec}$. The primary issues that remain are the demonstration of an automated power controller capable of maintaining a constant heater temperature regardless of thrust level and the definition of the operating 
conditions and thermal shielding necessary to minimize thermal losses. A larger version of the water resistojet has been constructed which was designed to operate at higher thrust and power leve15, yet maintain lower heater temperatures. This thruster will be the basis for the generation of detalled thermal and performance maps.

\section{Acknowledgements}

The authors wish to express their appreclation for the efforts of Robert G. Everett; Robert $D$. Gedeon, Jr., and James D. Wagner, of the NASA Lewis Research Center, who produced the research hardware critical to the evaluation of the liquidfed water resistojet.

\section{References}

1. Jones, R.E., Morren, W.E., Sovey, J.S., and Tacina, R.R., "Space Station Propulsion," NASA TM-100216, 1987.

2. Louviere, A.J., Jones, R.E., Morren, W.E., and Sovey, J.S., "Water-Propellant Resistojets for Man-Tended Platforms," IAF Paper 87-259, Oct. 1987. (NASA TM-100110).

3. Halbach, C.R., "10 mlb Biowaste Resistojet Performance," AIAA Paper 71-687, June 1971.

4. Lynch, R., "Development of a Water Vaporizer for Resistojet Applications," S-1244, Marquardt Company, Van Nuys, CA, Nov, 1972.

5. Stone, J.R., Gray, V.H., and Gutierrez, O.A., "Forced-Flow Once-Through Bollers," NASA SP-369, 1975.

6. Lowdermilk, W.H., Lanzo, C.D., and Siegel, B.L., "Investigation of Bolling Burnout and Flow Stability for Water Flowing in Tubes," NACA TN-4382, 1958.

7. Aladyev, I.T., Miropol sky, Z.L., Doroshchuk, V.E., and Styrikovich, M.A., "Bolling Crisis in Tubes," International Developments in Heat Transfer, ASME, New York, 1963, pp. 237-243.

8. Jeglic, F.A., "The Onset of Flow Oscillations in Forced-Flow Subcooled Bolling," Ph.D., Thesis, University of Notre Dame, 1965.

9. Jeglic, F.A., and Grace, T.M., "Onset of FLow Oscillations in Forced-Flow Subcooled Bolling," NASA TN D-2821, 1965.

10. Baker, 0.. "Multiphase Flow in Pipelines," Oil and Gas Journal, Vol. 56, No. 45, Nov. 10, 1958, pp. 156-167.

11. Baker, 0., "Simultaneous Flow of 011 and Gas," Oil and Gas Journal, Vol: 53, No. 12 , July 26, 1954, pp. 185-190, 192, 195.

12. Kozlov, B.K., "Forms of Flow of Gas-Liquid Mixtures and Their Stability Limits in Vertical Tubes," Trans. RJ418, Associated Technical Services, East Orange, NJ.
13. Kosterin, S.I., "Investigation of the Effect of the Diameter and the Position of Pipe upon the Hydraulic Resistance and the Structure of the Flow of a Gas-Liquld Mixture," Trans. No. 3085, Henry. Brutcher. Technical

Translation, Altadena, CA.

14. Govier, G.W., Radford, B.A, and Dunn, J.S.C.: "The Upward Vertical Flow of Air-Water Mixtures: I. Effect of Air and Water-Rates on Flow Pattern, Holdup, and Pressure Drop," Canadian Journal of Chemical Engineering, Vol. 35, No. 3, Aug. 1957, pp. 58-70.

15. Govier, G.W., and Short, W.L., "The Upward Vertical Flow of Air-Water Mixtures: II. Effect of Tubing Diameter on Flow Pattern, Holdup, and Pressure Drop," Canadian Journal of Chemical Engineering, Vol. 36, No. 5, Oct. 1958, pp. 195-202.

16. Krasiakova, L.I., "Some Characteristics of the Flow of a Two-Phase Mixture in.a Horizontal Pipe," AERE-LIB/TRANS-695; Atomic Energy Research Establishment, Jan. 1957. (Translated by $P$. Collins from Zhurnal Tekhnicheskol Flzika, Vol..22, 1952, pp. 654-669).

17. Jakob, M., Leppert, G., and Reynolds, J.B., "Pressure Drop During Forced-Circulation Bolling," Chemical Engineering Progress Symposfum Series, Vol. 52, No. 18, 1956, pp. 29-36.

18. Tippets, F.E., "Critical Heat Fluxes and Flow Patterns in High-Pressure Boiling Water Flows," Journal of Heat Transfer, Vol. 86, No. 1, Feb. 1964, pp. 12-22.

19. Hosler, E.R., "Flow Patterns in High Pressure Two-Phase (Steam-Water) Flow with Heat Addition." WAPD-TM-658, Bettis Atomic Power Lab., Pittsburgh, PA, June 1967.

20. Janssen, E., "Two-Phase Flow Structure in a Nine-Rod Chánnel, Steam-Water at 1000 psia," GEAP-5480, General Electric Co., June 1967.

21. Vohr, J.H., "A Photographic Study of Bolling Flow," NYO-9650, Columbia University, Oct. 25, 1963.

22. Johnson, H.A., Schrock, V.E., Selph, F.B., and Fabic, S., "Reactor Heat Translent Research," SAN-1002, University of California, Berkeley, CA, Nov. 1961.

23. Martenson, A.J., "Transient Bofling in Small Rectangular Channels," Ph.D. Thesis, University of Pittsburgh, 1962.

24. Dengler, C.E., "Heat Transfer and Pressure Drop for Evaporation of Water in a Vertical Tube," Ph.D. Thesis, Massachusetts Institute of Technology, 1952. 
25. Rohsenow, W.M., "Heat Transfer Associated with Nucieate Bolling," I953 Heat Transfer and Flufd Mechanlcs Institute, Stanford University Press, stanford, CA, 1953, pp. 123-141.

26. Engelberg-Forster, K., and Greff, R., "Heat Transfer to a Boliling Liquid - Mechanism and Correlations," Journal of Heat Transfer, Vol. 81. No. 1, Feb. 1959, pp. 43-53.

27. Forster, H.K., and Zuber, N., "Dynamics of Vapor Bubbles and Bolling Heat Transfer," AIChE Journal, Vol. 1, No. 4, Dec. 1955, pp. 531-535.

28. Pape11, S.S:, "Subcooled Bolling Heat Transfer Under Forced Convection in a Heated Tube," NASA TN D-1583, 1963.

29. Dengler, C.E., and Addoms, J.N., "Heat Transfer Mechanism for Vaporization of Water In a Vertical Tube," Chemical Engineering Progress Symposium Sertes, Vol. 52, No. 18, 1956, pp. 95-103.

30. Wright, R.M., "Downflow Forced-Convection Bolilng of Water in Uniformly Heated Tubes," UCRL-9744, University of California, Aug. 1961 .

31. Schrock, V.E., and Grossman, L.M., "Forced Convection Bolling Studies," TID-14632, University of Californla, Lawrence Radiation Lab. , Nov. 1959.

32. Collier, J.G., and Pulling, D.J., "Heat Transfer to Two-Phase Gas-Liquld Systems, Part II: Further Data on Steam-Water Mixtures," AERE-R-3809, United Kingdom Atomic Energy Authority, 1962.

33. Chen, J.C., "A Correlation for Bolling Heat Transfer to Saturated Fluids in Convective Flow," ASME Paper 63-HT-34, Aug. 1963.

34. Mumm, J.F., "Heat Transfer to Bolling Water Forced Through a Uniformly Heated Tube," ANL-5276, Argonne National Lab., Nov. 1954.

35. Altman, M., Norris, R.H., and Staub, F.W., "Local and Average Heat Transfer and Pressure Drop for Refrigerants Evaporating in Horizontal Tubes," Journal of Heat Transfer, Voi. 82, No. 3, Aug. 1960, pp. 189-198.

36. Sachs, P., and Long, R.A.K., "A Correlation for Heat Transfer in Stratified Two-Phase Flow with Vaporization," International Journal of Heat and Mass Transfer, Vol. 2, No. 3, Apr. 1961, pp. 222-230.

37. Wallerstedt, R.L., and Miller, D.B., "Mercury Rankine Program Development Status and Multiple System Application," AIAA Specialists Conference on Rankine Space Power Systems, Vol. 1, CONF-651026, 1965, pp. 3-51.

38. Gresho, P.M., Poucher, F.W., and Wimberly, F.C. , "Mercury Rankine Program System Test Experience," AIAA Spectalists Conference on Rankine Space Power Systems, Vol. I, CONF-651026, 1965, pp.52-102.
39. Gordon, R., and Slone, H.O., "SNAP-8 Development Status," AIAA Specialists Conference on Rankine Space Power Systems, Vol. 1, CONF-651026, 1965, pp. 103-138.

40. Kreeger, A.H., Hodgson, J.N., and Sellers, A.J., "Development of the SNAP-8 Boller," AIAA Speclalists Conference on Rankine Space Power Systems, Vol. 1, CONF-651026, 1965, pp. 285-306.

41. Owhadi, A., "Bolling in Self-Induced Radial Acceleration Fields," Ph.D. Thesis, Oklahoma State University, 1966.

42. Kikin, G.M., Peelgren, M.L., Phillips, W.M., and Davis, J.P.. "Shell Side Liquid Metal Boller," U.S. Patent 3,630,276, Dec. 28, 1971.

43. Gray, V.H., Marto, P.J., and Joslyn, A.W., "Boliling Heat-Transfer Coefficients, Interface Behavior, and Vapor Quality in Rotating Boller Operating to 475 G's," NASA TN D-4136, 1968.

44. Marto, P.J., and Gray, V.H., "Effects of High Accelerations and Heat. Fluxes on Nucleate Bolling of Water in an Axisymmetric Rotating Boller," NASA TN D-6307, 1971.

45. Lawler, M.T., and Ostrach, S., "A Study of Cyclonic Two-fluid Separation," FTAS/TR-65-2, Case Institute of Technology (AFOSR-65-1523, Ava11. NTIS, AD-621524), June 1965.

46. Haag, T.W., and Curran, F.M., "Arcjet Starting Rellability: A Multistart Test on Hydrogen/Nitrogen Mixtures," AIAA Paper 87-1061, May 1987. (NASA TM-89867).

47. Keenan, J.H., et al. Steam Tables, Joseph Wlley and Sons, New York, 1969.

48. McBride, B.J., et al.. "Thermodynamic Properties to $6000^{\circ} \mathrm{K}$ for 210 Substances Involving the First 18 Elements," NASA SP-3001, 1963.

49. Grisnik, S.P., Smith, T.A., and Saltz, L.E., "Experimental Study of Low Reynolds Number Nozzles," AIAA Paper 87-0992, May 1987. (NASA TM-89858).

50. Whalen, M.V., "Low Reynolds Number Nozzle Flow Study," NASA TM-100130, 1987.

51. Gruber, R.P., Private Communication, NASA Lewis Research Center, Cleveland, OH, Apr. 1988. 
TABLE I. - WATER RESISTOJET PERFORMANCE DATA

\begin{tabular}{|l|r|r|r|r|r|r|r|r|r|r|r|}
\hline Feed pressure, kPa & 756 & 786 & 738 & 744 & 1220 & 1740 & 1670 & 1740 & 1720 & 1790 & 2240 \\
Voltage, V & 46.5 & 48.0 & 46.5 & 47.0 & 54.5 & 56.5 & 58.0 & 58.5 & 59.7 & 62.0 & 66.5 \\
Current, A & 9.58 & 9.87 & 9.53 & 9.65 & 11.30 & 11.70 & 12.00 & 12.10 & 12.20 & 12.70 & 13.60 \\
Power, W & 445 & 474 & 443 & 454 & 616 & 661 & 696 & 708 & 728 & 787 & 904 \\
Mass flow rate, mg/sec & 104 & 104 & 108 & 101 & 149 & 169 & 163 & 165 & 164 & 167 & 191 \\
Thrust, mN & 170 & 174 & 177 & 181 & 247 & 272 & 280 & 286 & 295 & 312 & 360 \\
Specific impulse, sec & 167 & 171 & 167 & 183 & 169 & 164 & 175 & 177 & 183 & 190 & 192 \\
Power/thrust, W/mN & 2.62 & 2.72 & 2.50 & 2.51 & 2.49 & 2.43 & 2.49 & 2.48 & 2.47 & 2.52 & 2.51 \\
Power/mass flow, MJ/kg & 4.28 & 4.56 & 4.10 & 4.49 & 4.13 & 3.91 & 4.27 & 4.29 & 4.44 & 4.71 & 4.74 \\
Overall efficiency & 0.312 & 0.307 & 0.327 & 0.358 & 0.332 & 0.331 & 0.346 & 0.350 & 0.364 & 0.370 & 0.375 \\
Heater temperature, K & & & & & & & & \\
Superheater inlet & 875 & 918 & 851 & 1026 & 898 & 927 & 929 & 858 & 1098 & 971 & 994 \\
Superheater middle & 1029 & 1051 & 981 & 1100 & 1047 & 1049 & 1067 & 1067 & 1171 & 152 & 1181 \\
Superheater exit & 1079 & 1101 & 1026 & 1126 & 1100 & 867 & 975 & 995 & 1074 & 1212 & 1242 \\
\hline
\end{tabular}

\section{$\begin{array}{lll}\text { PREHEATING NUCLEATE } & \text { LIQUID-FILM } & \text { DROPLET VAPORIZATION AND } \\ \text { BOILING } & \text { EVAPORATION } & \text { VAPOR SUPERHEATING }\end{array}$}

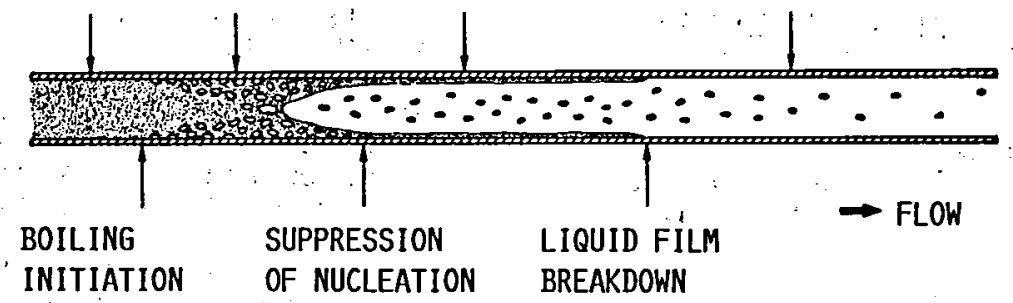

FIGURE 1. - TYPICAL HEAT-TRANSFER REGIMES FOR BOILING IN FLOW CHANNEL:

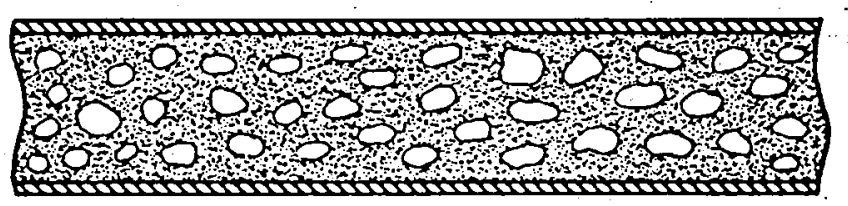

(a) BUBBLY FLOW.

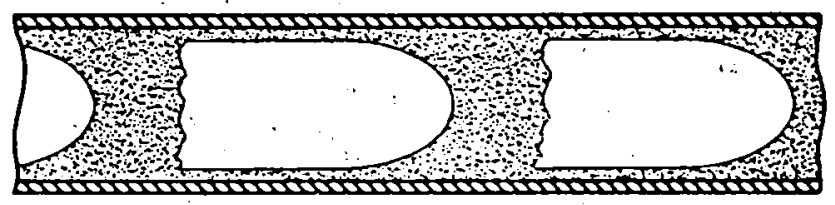

(b) SLUG FLOW.

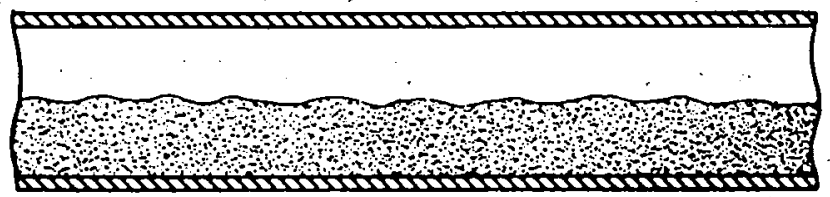

(c) STRATIFIED FLOW.

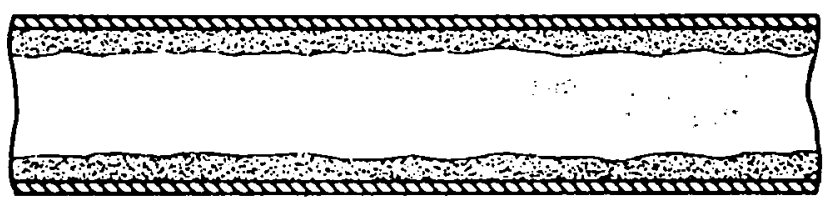

(d) ANNULAR FLOW.

FIGURE 2. - TYPICAL TWO-PHASE FLOW PATTERNS. 


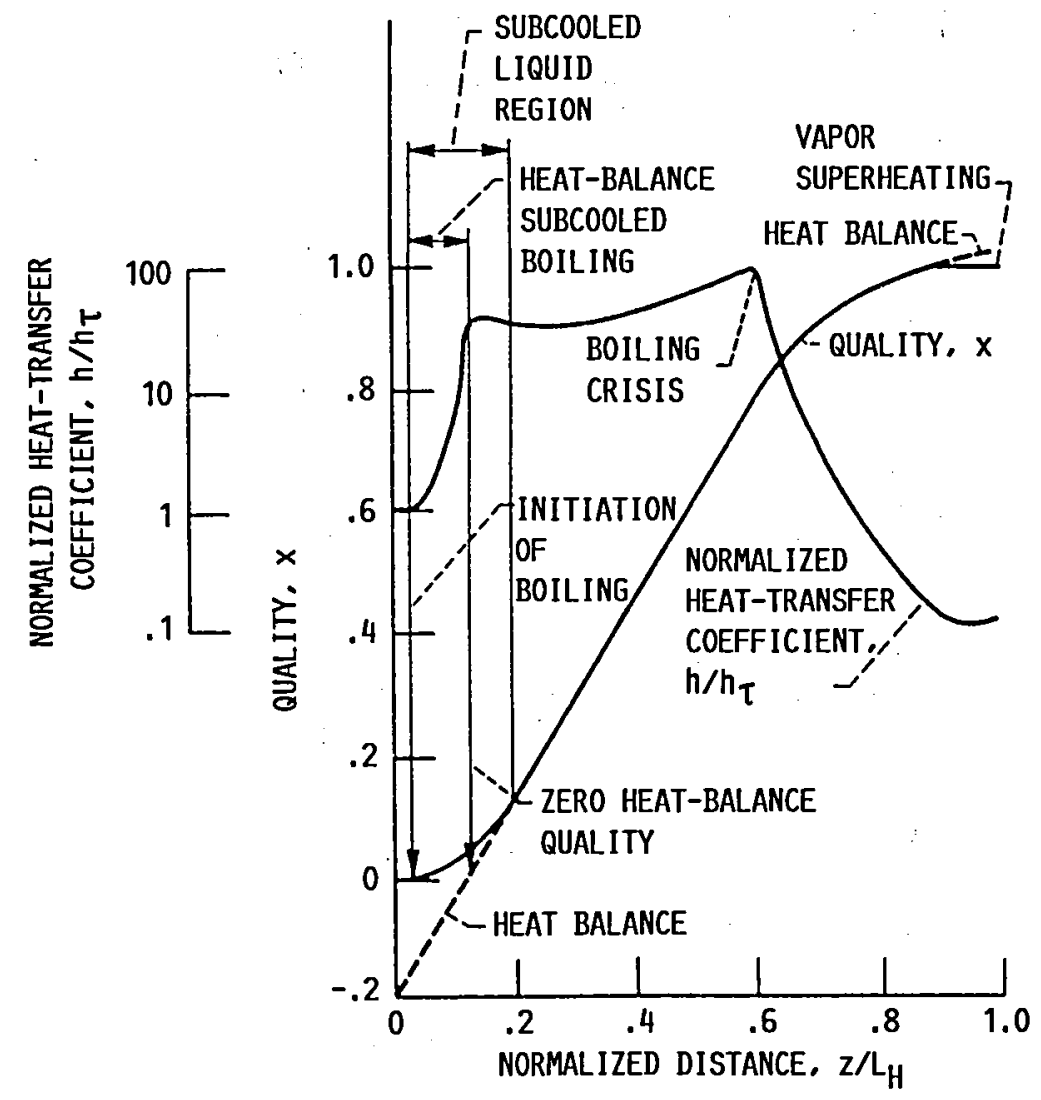

FIGURE 3. - TYPICAL BOILING HEAT-TRANSFER PERFORMANCE.

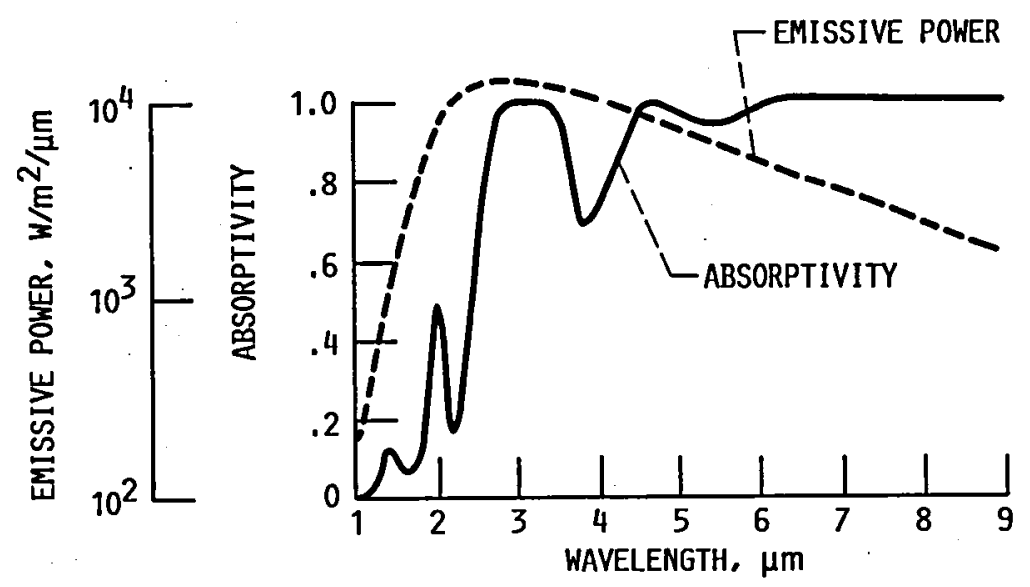

FIGURE 4. - SPECTRAL ABSORPTIVITY FOR WATER AND BLACKBODY EMISSIVE POWER DISTRIBUTION FOR $1000 \mathrm{~K}$ SOURCE. WATER FILM THICKNESS $=0.1 \mathrm{~mm}$. 


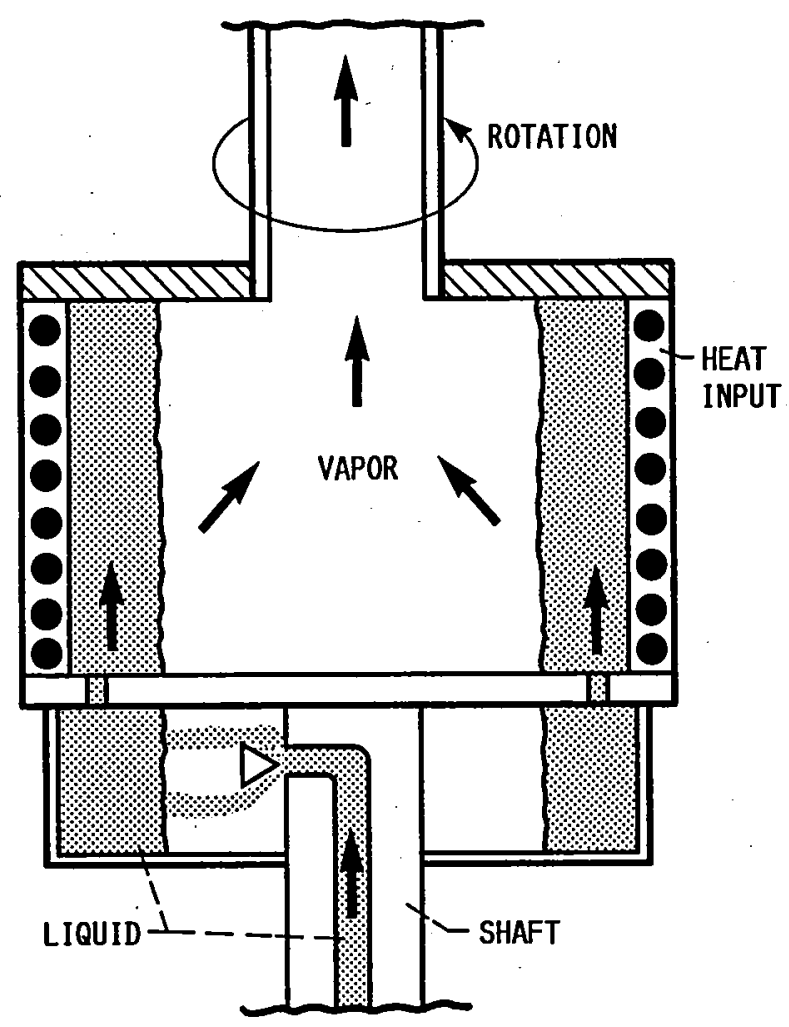

FIGURE 5. - ROTATING BOILER CONCEPT.
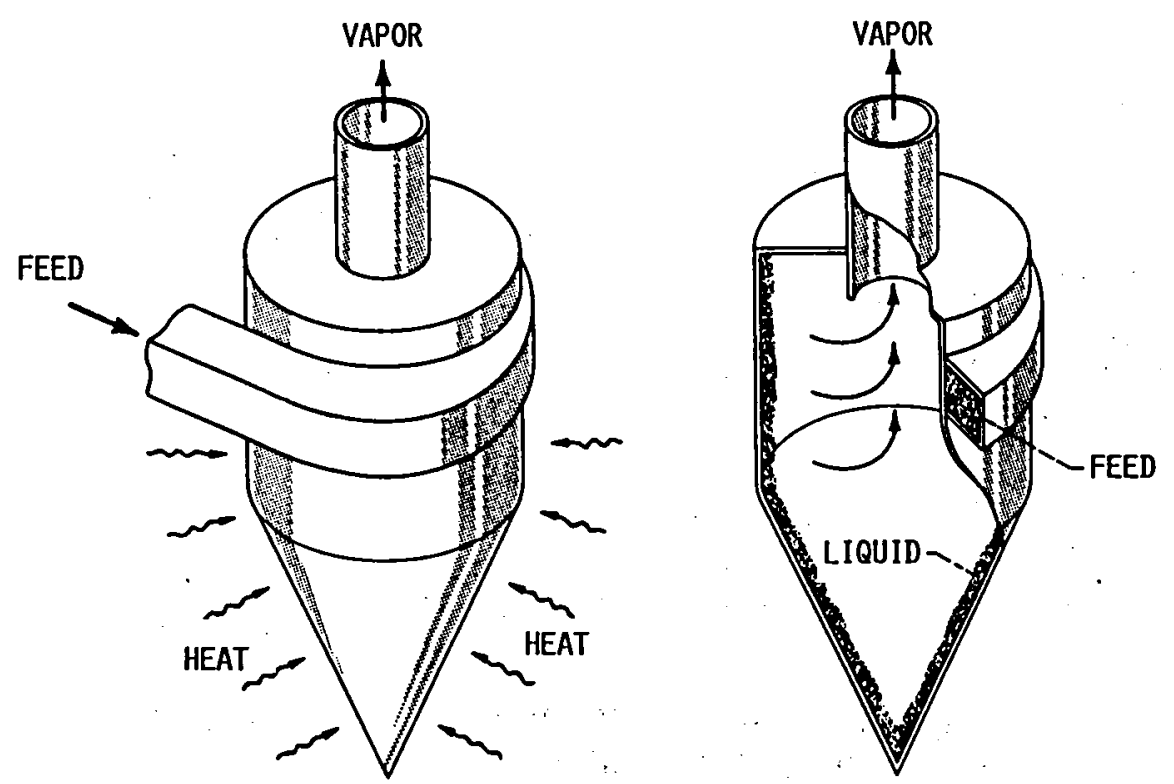

FIGURE 6. - CYCLONE BOILER CONCEPT. 


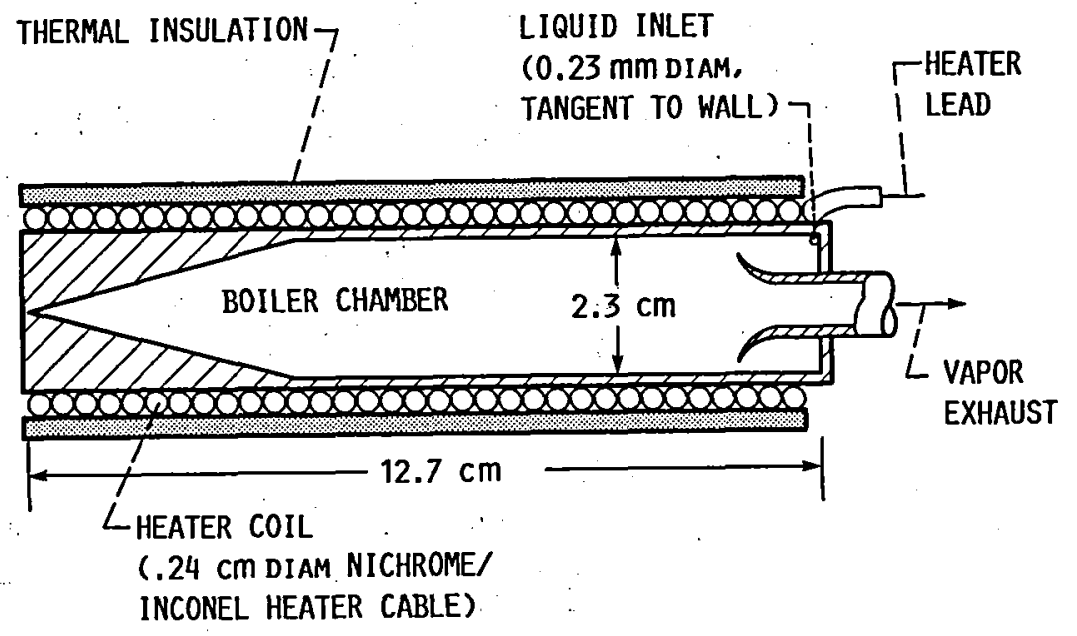

FIGURE 7. - LABORATORY MODEL CYCLONE VAPORIZER (FIRST ITERATION). 
A INTERNAL THERMOCOUPLE LOCATIONS

* eXTERNAL thermoCOUPLE LOCATIONS

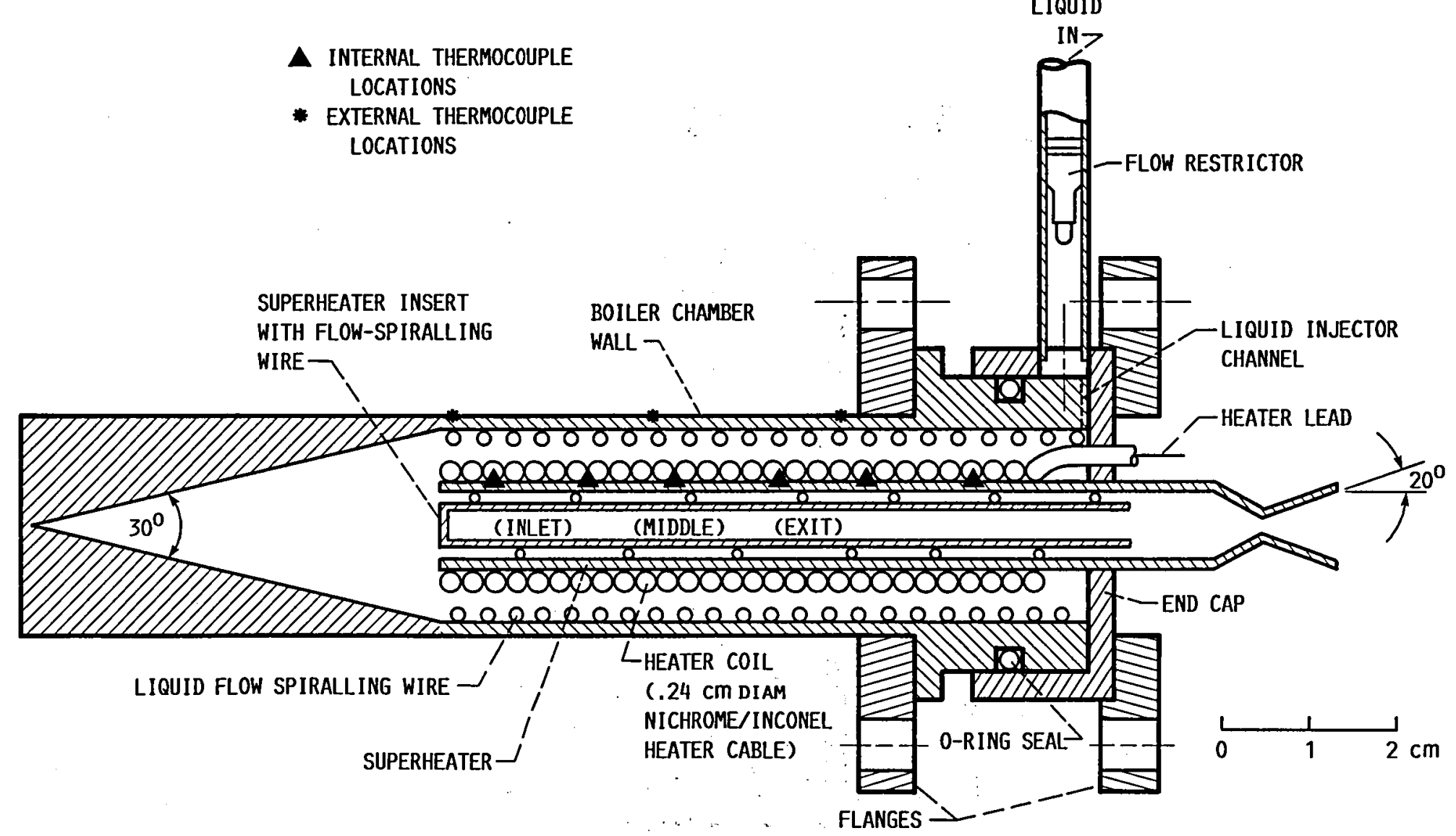

FIGURE 8. - SECTIONAL DRAWING OF LIQUID-FED WATER RESISTOJET (ENHANCED CYCLONE VAPORIZER WITH NOZZLE ADDED). 


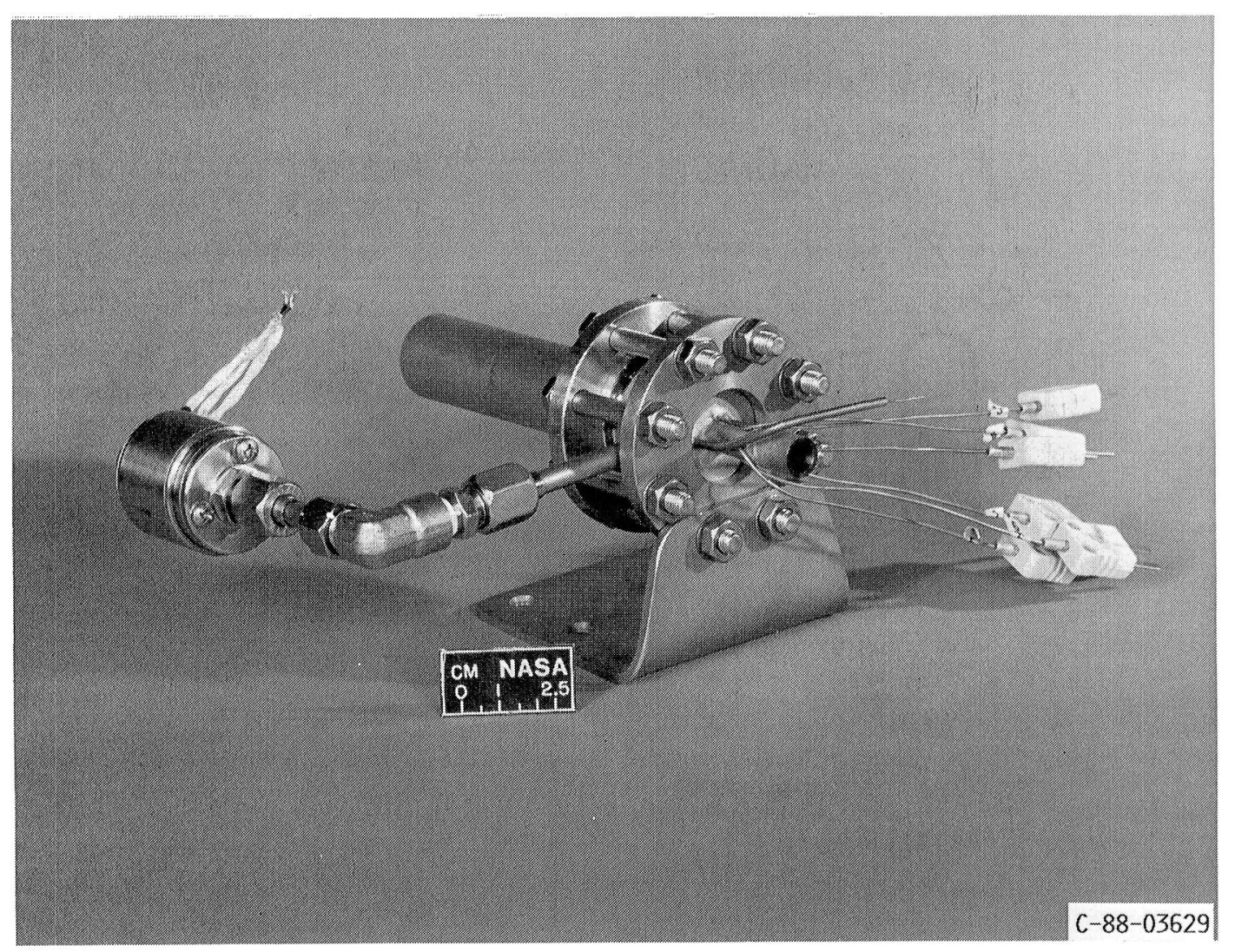

(a) ASSEMBLED.

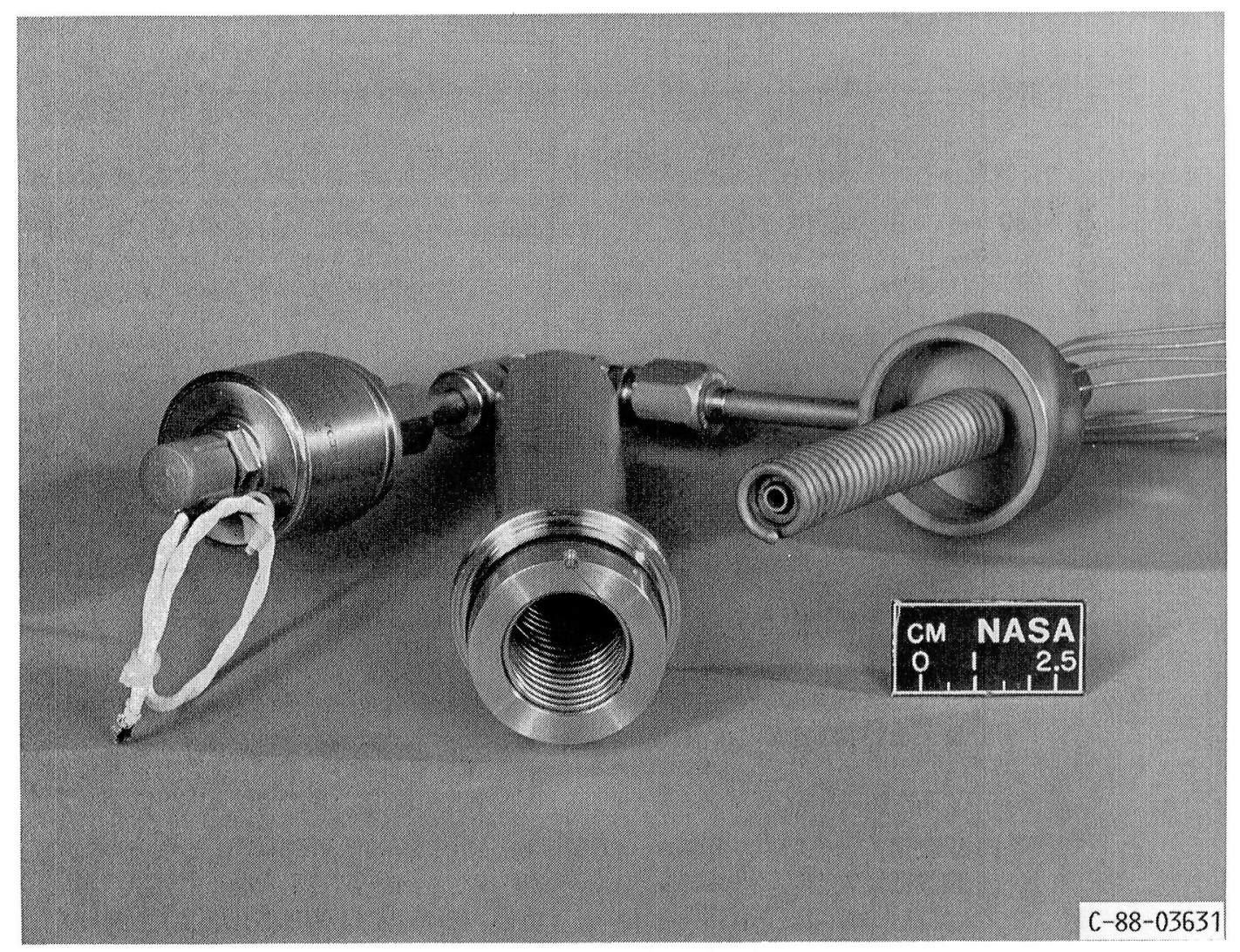

(b) DISASSEMBLED.

FIGURE 9. - LIQUID-FED WATER RESISTOJET. 


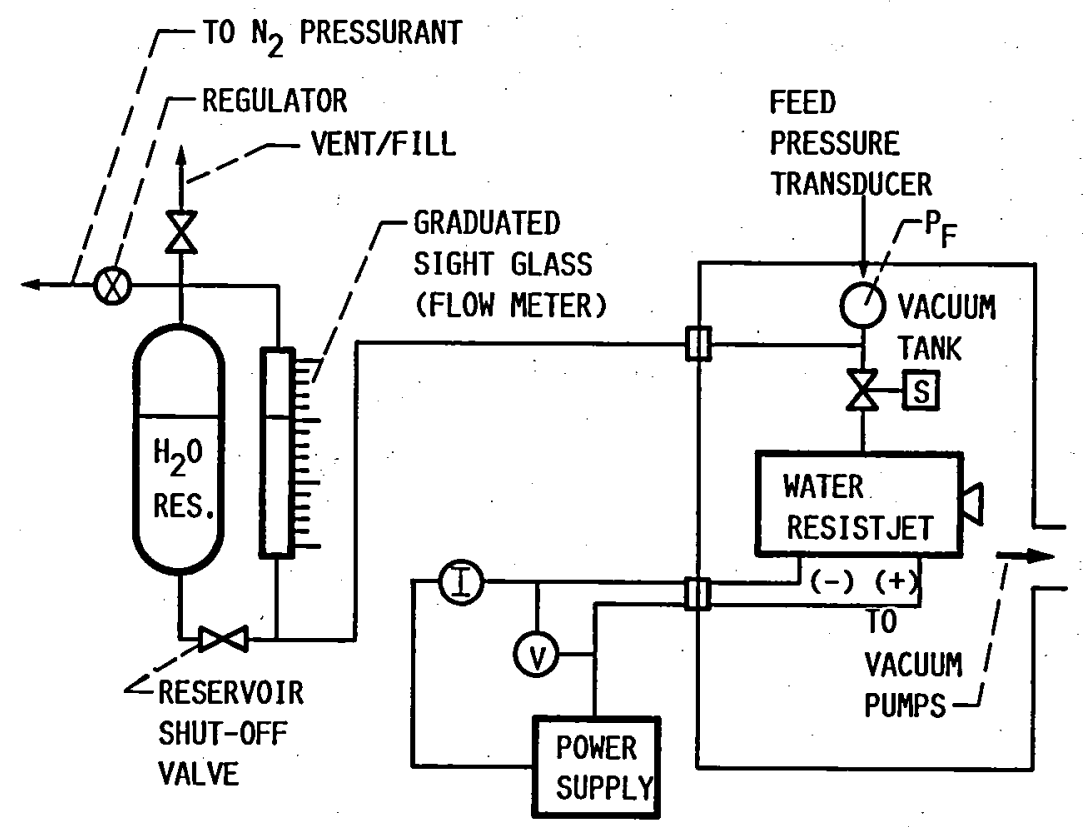

FIGURE 10. - WATER RESISTOJET TEST APPARATUS SCHEMATIC (THRUST STAND DELETED).

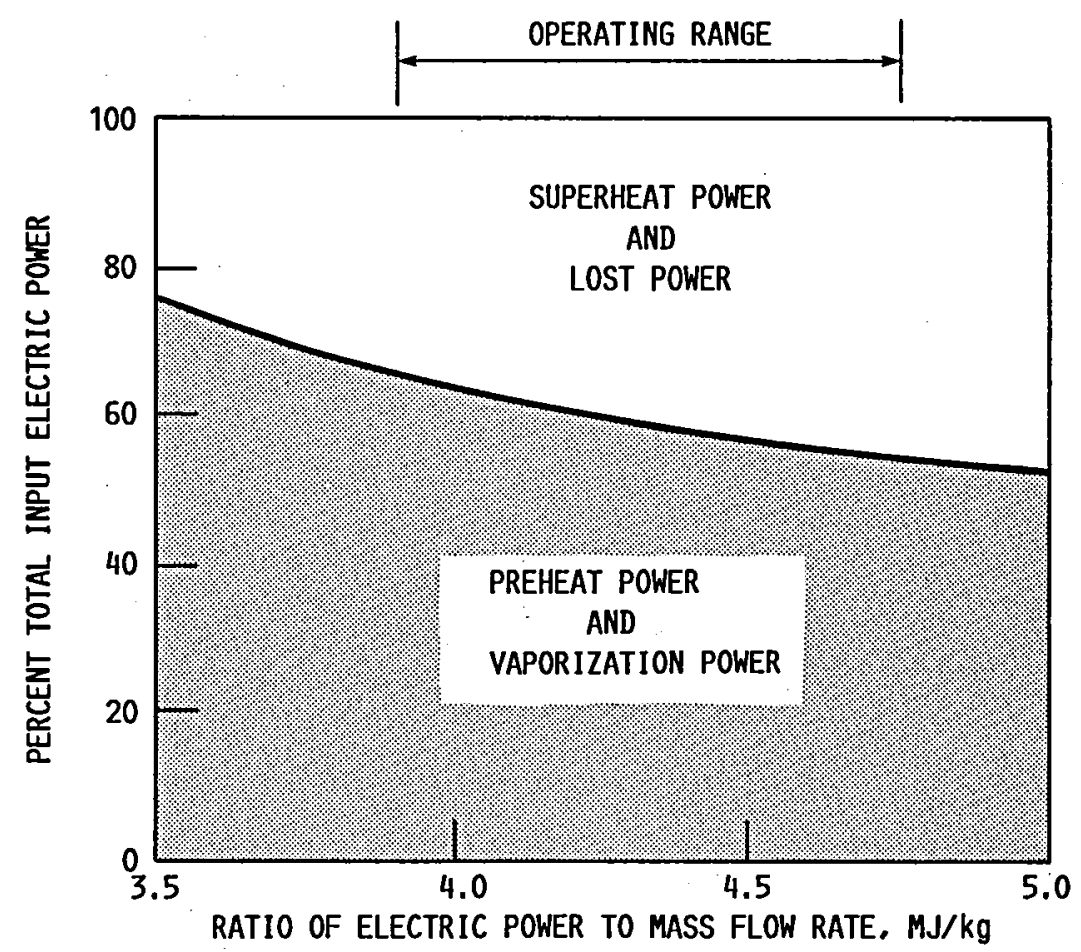

FIGURE 11. - FRACTIONS OF INPUT ELECTRIC POWER DISSIPATED IN PREHEATING AND VAPORIZING AND IN SUPERHEATING AND LOSSES VERSUS RATIO OF INPUT POWER TO MASS FLOW RATE FOR LIQUID-FED WATER RESISTOJET. 


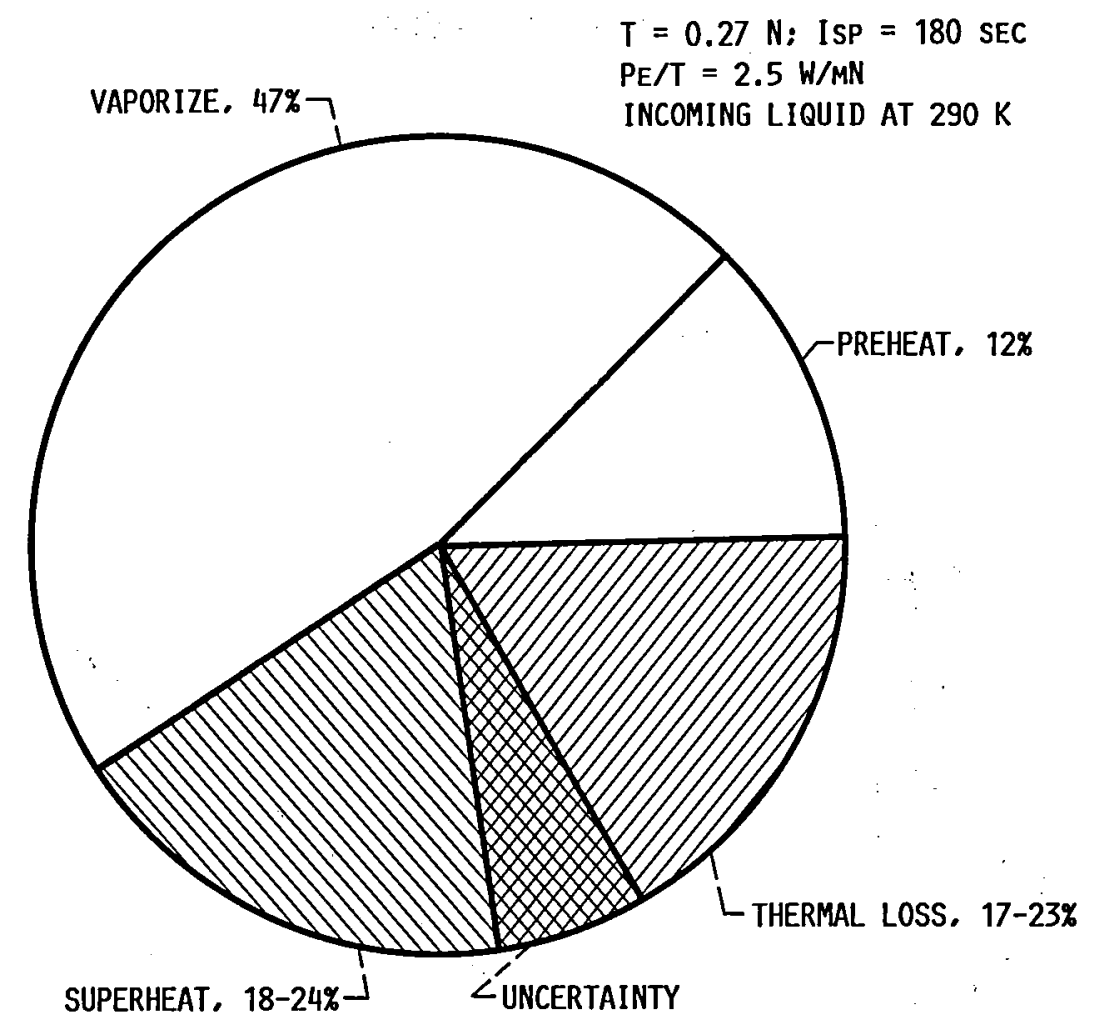

FIGURE 12. - POWER DISTRIBUTION FOR LIQUID-FED WATER RESISTOJET.

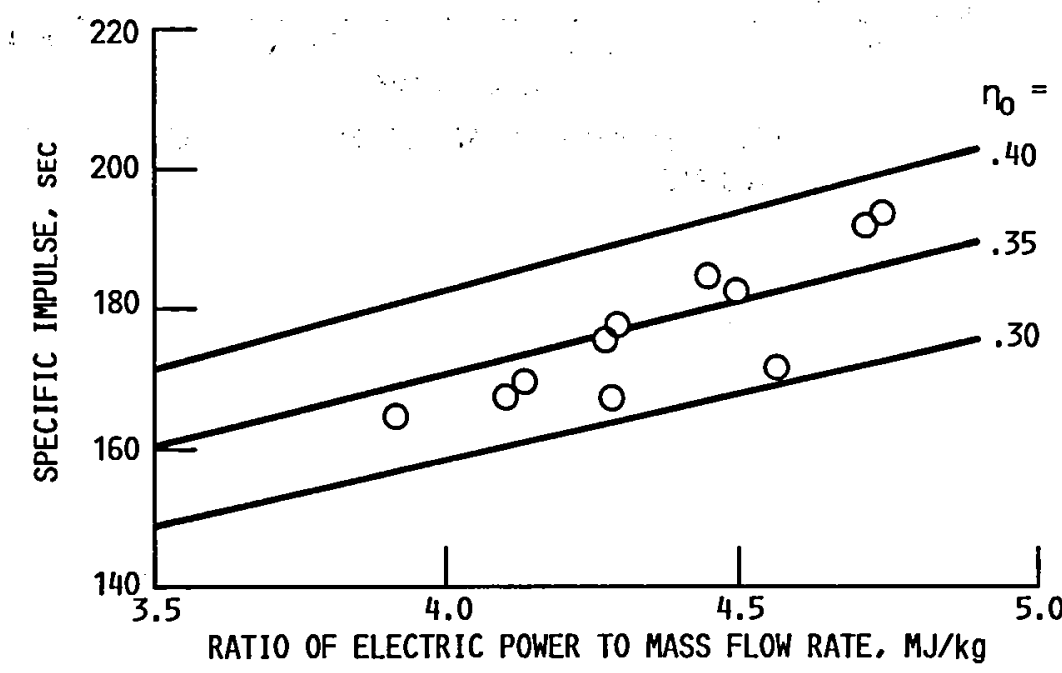

FIGURE 13. - SPECIFIC IMPULSE VERSUS RATIO OF ELECTRIC POWER TO MASS FLOW RATE FOR WATER RESISTOJET. 


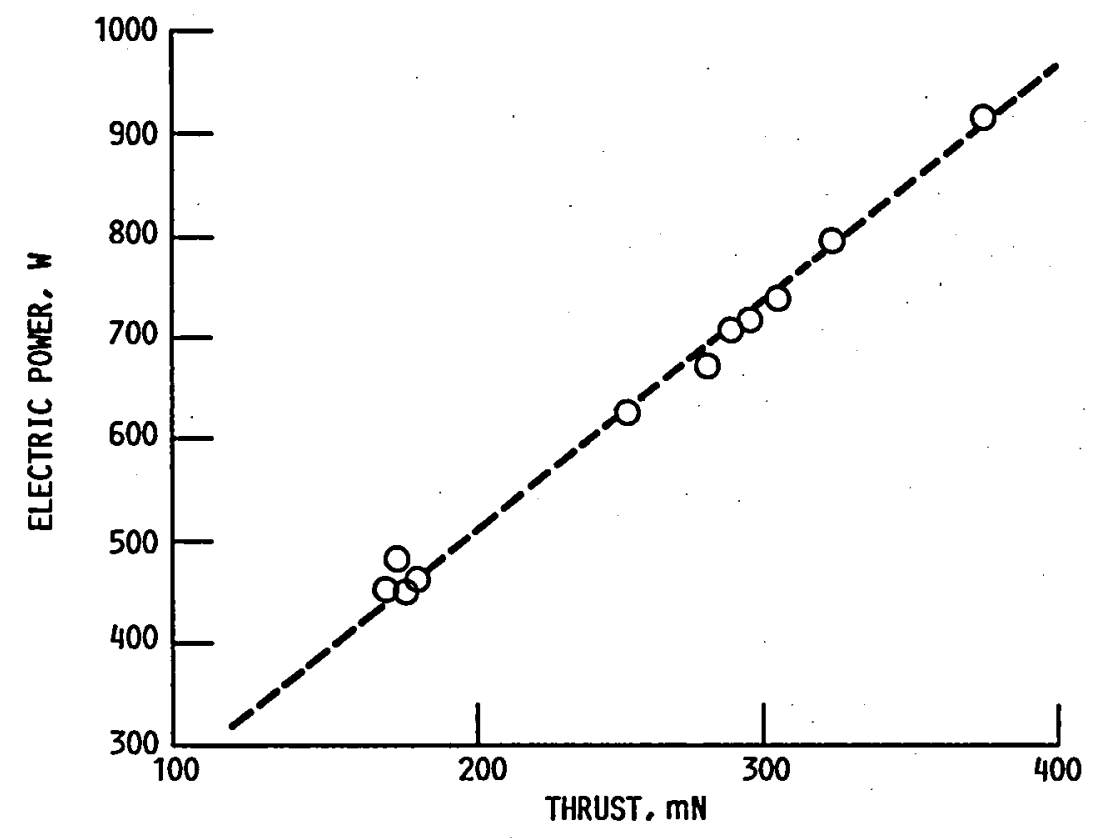

FIGURE 14. - ELECTRIC POWER VERSUS THRUST FOR WATER RESISTOJET. 


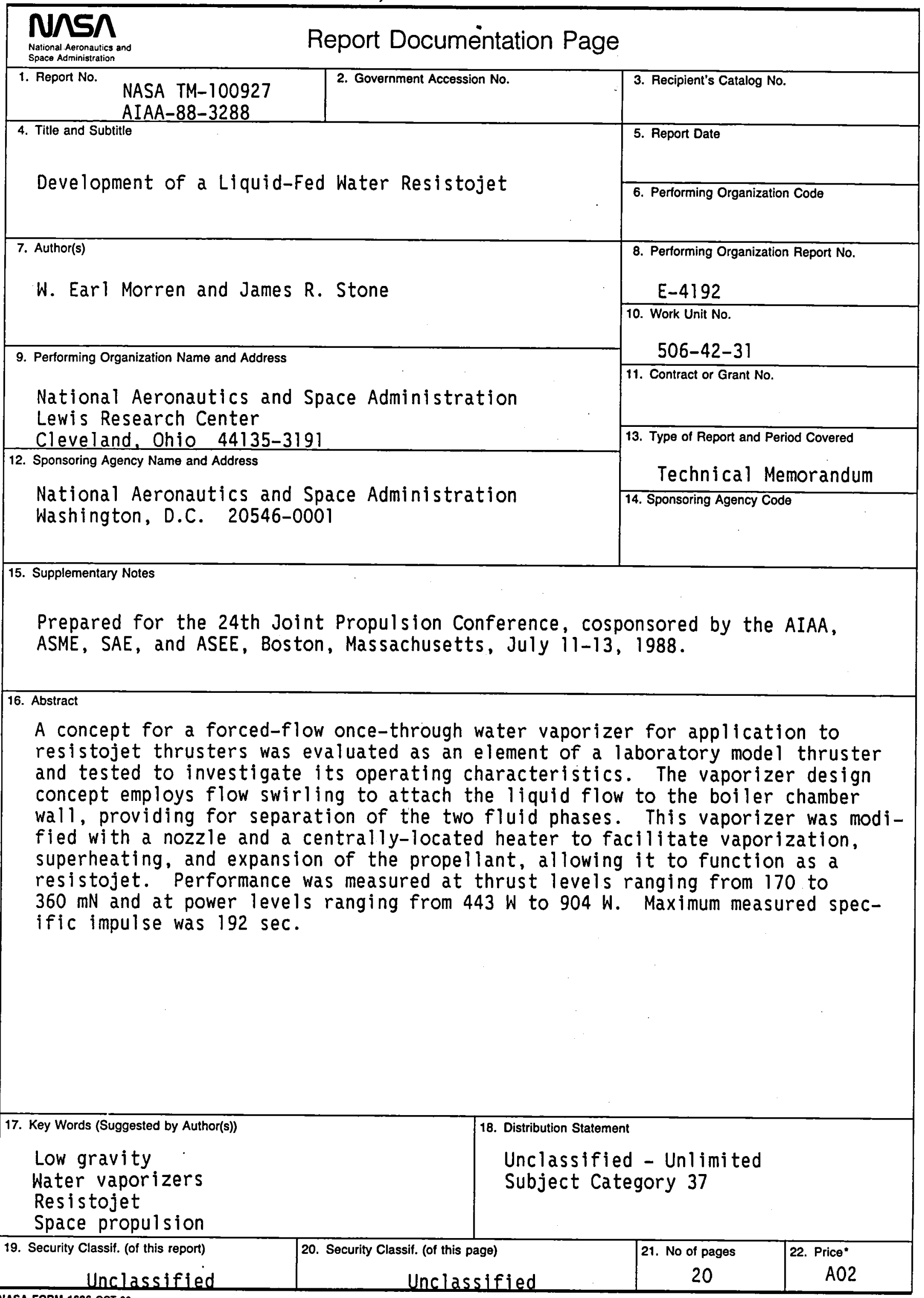


National Aeronautics and. Space Administration

Lewis Research Center

Cleveland, Ohio 44135

\section{FOURTH CLASS MAIL}

ADDRESS CORRECTION REQUESTED
Official Business

Penalty for Private Use $\$ 300$

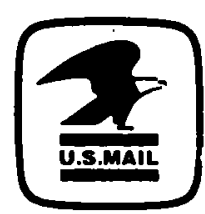

Postage and Fees Paid National Aeronaulics and

Space Administration

NASA-451 